\title{
O PARQUE NO DESENHO URBANO
}

\section{PARKS AND URBAN DESIGN}

Miranda Martinelli Magnoli

Professora titular da Faculdade de Arquitetura e Urbanismo da Universidade de São Paulo (FAUUSP).

E-mail:mmemm@uol.com.br

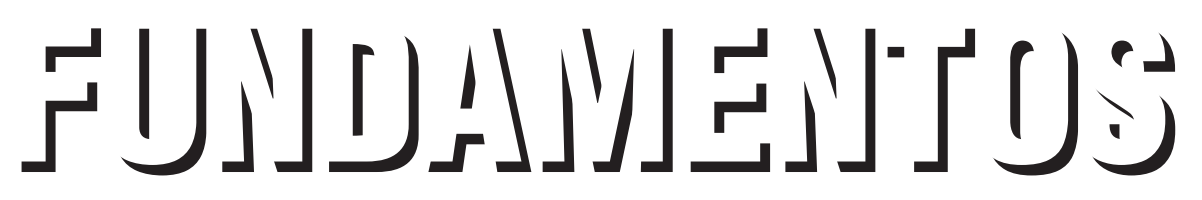




\section{RESUMO}

Os parques urbanos são inseridos na urbanização como parte dos espaços livres de edificação. Sob esse aspecto, sua distribuição nas várias escalas de urbanização é parte de um projeto da sociedade sobre sua cidade como um todo. Por outro lado, o desenho do espaço em si pode ser lido em face dos contextos em que são implantados como parte dos mecanismos de controle social. São levantados sucintamente estes aspectos para receber contribuições em área que consideramos de intensa implicação no desenho urbano.

Palavras-chave: Parque, desenho urbano, espaço livre.

\section{ABSTRACT}

The urban parks take part of the urban open spaces system and their existence depends on the social decisions. This paper focuses the insertion of the modern parks in the Brazilian modern city.

Key words: Park, urban design, and open space. 


\section{O PARQUE NO DESENHO URBANO}

\section{PARKS AND URBAN DESIGN}

\section{Introdução}

Os parques públicos são, inicialmente (1789), propostos em Munich como espaços de recreação pública. Tira-se partido, na maior parte dos espaços, de fortificações em desuso. Com a acepção atual de áreas especificamente reservadas para utilização pela população, são desenvolvidos, no século XIX, por desenhos em áreas da Coroa Britânica (St. James Park e Regent's Park/1828). O primeiro sistema de parques desenhado para Paris não teve como critério fundamental a utilização pela população. É em Nova York, com o Central Park, que se implanta o maior parque público que seria desenhado com critério, na época, julgado de necessidade da população urbana.


Fotos 1 e 2: Vistas gerais - Regent's Park, Londres

Crédito: Josefina Capitani, 2001

Foto 2 


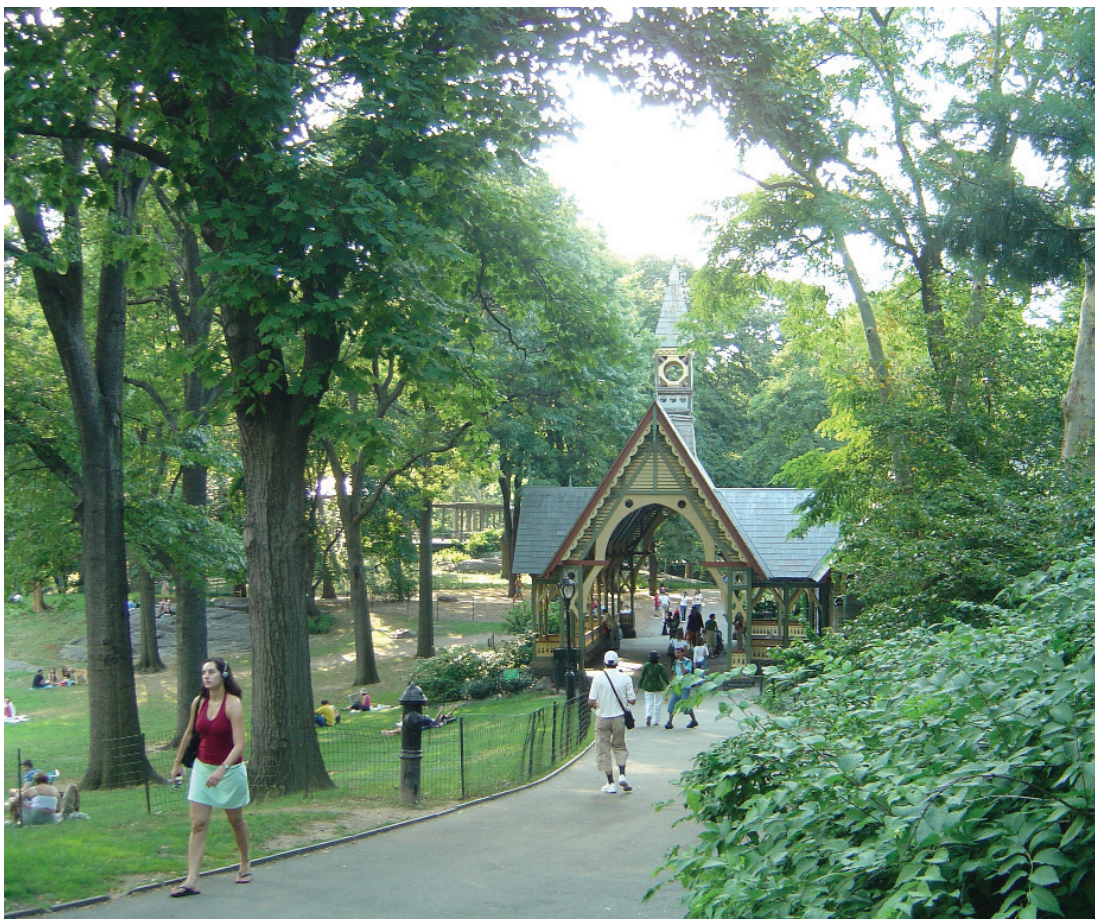

Foto 3: Vistas gerais - Central Park, Nova York Crédito: Silvio Macedo, 2004

Setores especiais dos espaços livres de edificação são ainda entre nós vistos de maneira superficial, como quantidades de solo, como suporte da flora ou como "pulmões" da cidade. Fragmentados quer no complexo espacial quer no das políticas urbanas e culturais são relegados como aspectos complementares, de sofisticação e supérfluos, como base para o esplendor de objetos arquitetônicos. No entanto, com forte peso na configuração de modelo urbano, são, freqüentemente, descontinuidades físicas inadequadas no tecido urbano ou na polinucleação global. Localizações de distribuição de carências e de excessos, no mínimo, por falta de globalização e simultânea especificidade da questão. Porém, os parques são efeitos; o processo não parece tão linear de causa e efeito, aceito "o espaço como instância da sociedade" (Milton Santos).

\section{Os Parques Urbanos São Parte do Sistema de Espaços Livres de Edificações}

O espaço livre é aqui entendido como todo espaço (e luz) nas áreas urbanas e em seu entorno, não-coberto por edifícios. A amplitude que se pretende diz respeito ao espaço e não somente ao solo e a água, não-cobertos por edifícios; também diz respeito aos espaços que estão ao redor, na auréola da urbanização, e não somente internos, entre tecidos urbanos'. Por esse entendimento de espaço livre (†odo solo e toda água não-cobertos por edifícios) o vínculo do espaço é fundamentalmente de localização em relação aos edifícios, isto é, para com as pessoas que os ocupam, em circulação ou em permanência. $\bigcirc$ enfoque de espaço livre enquanto objeto de desenho só é relevante desde que analisado em face das atividades e necessidades do homem urbano.

A definição e o enfoque de espaço livre faz com que seja secundária a questão da quantidade de espaços livres (quanto-indíces); transforma, porém, a importância relativa a onde estão os espaços livres e, repetimos, articula o onde com as permeabilidades dos edifícios e da urbanização (quando se interpretar a questão) nas diversas escalas desde o bairro, conjunto de bairros (distritos), núcleos urbanos, metrópoles, sub-regiões, regiões (Ver Figuras la e 1b). 




Figura 1a: Representando as edificações em quadrados escuros sobre o espaço livre; em cinza observa-se que a quantidade é a mesma para qualquer arranjo; 0 que altera é a distribuição vinculada a outras morfologias
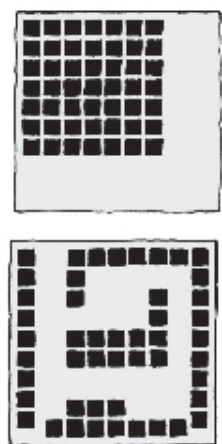

\section{Espaço Livre}

de Edificaçóes

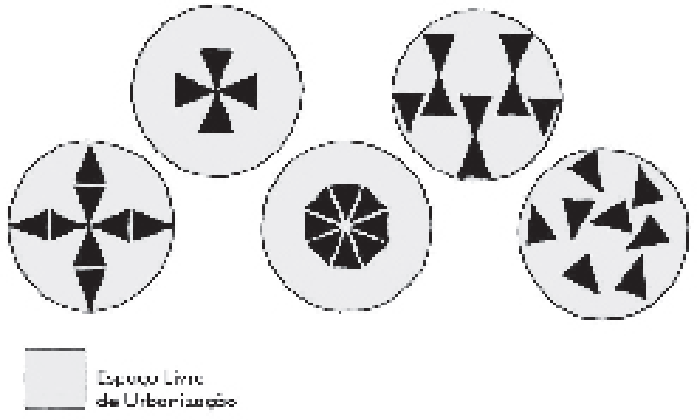

Figura 1b: Representando a urbanização e o espaço exterior, volta-se a observar a variação da distribuição com a mesma quantidade. O segundo exemplo mostra maior adensamento com acréscimo de espaço livre. A distribuição do espaço livre tem implicações com a concentração ou as polinucleações

Créditos: Miranda Magnoli

Assim sendo, o espaço livre de edificações e de urbanização constitui-se em um contínuo cuja distribuição deve ser tal, que propicie o enriquecimento das atividades do homem urbano, na medida em que, visto em sua globalidade, a difícil e abstrata polêmica da quantificação passa a ser um falso problema, pois a quantidade é constante em seu todo; o que varia é a distribuição e a conFIGURAção dessa distribuição nas diversas escalas da urbanização.

A apropriação dos espaços pelo homem para suas necessidades e atividades é criada em âmbitos locais, setoriais, urbanos, metropolitanos, sub-regionais e regionais em função da proximidade espacial. A proximidade espacial, movimento, exige permeabilidade entre os espaços por meios diversificados e amplos de locomoção. A distribuição de espaços livres para serem apropriados pelo homem (sistema de parques) fica vinculada às maneiras de acessos disponíveis em cada uma das escalas de urbanização, e à freqüência dos usuários. Freqüência, utilização, apropriação em sentido amplo diz respeito à duração e periodicidade de tempo disponível. Isso conduz esquematicamente (e ainda grosseiramente) a usos diários, semanais, de feriados, de férias curtas ou prolongadas. É pela relação entre o uso diário e a duração reduzida que se pode observar que são espaços os quais devem estar próximos da habitação, de nível local. Para atividades de longa duração, o tempo de acesso passa a ter pequena interferência, permitindo localizações regionais. Há toda uma gama de diversificação de distribuição espacial que fica inserida entre os dois extremos e é função da freqüência dos usuários e da localização e facilidades de acesso.

Outro é o caso em que no diagnóstico das capacidades do meio físico, além de indicar-se os pontos críticos de impacto (função de localização e de eliminação de resíduos), os subsídios para diretrizes de atividades ao ar livre, enfatizam-se locais de potencial natural disponível para utilização. Nesse caso, mesmo com curta duração, será o caso de propiciar acessos a essas localizações. $\bigcirc$ mesmo se dá em atividades que exigem localizações específicas diante de requisitos topográficos, climáticos ou geográficos.

O atendimento do cidadão nas várias escalas de urbanização e a diversidade de apropriação em atividades variadas, diversificadas, específicas ou não, "ativas" ou "passivas", para todos os cidadãos, em idade, sexo, isolados ou em grupos, leva à distribuição de espaços diversificados no interior, na periferia e no exterior da mancha urbana. Diversificados em configuração, em acessibilidade, em desenho, em manutenção. 
Espaços livres de edificações ou de urbanização são pressupostamente os mais acessíveis por todos os cidadãos; os mais apropriáveis perante as oportunidades de maior autonomia de indivíduos e grupos; os que se apresentam com mais chance de controle pela sociedade como um todo, já que abertos, expostos, acessíveis; enfim, aqueles os quais podem ser os mais democráticos possíveis, enquanto significado intrínseco da expressão espaço urbano.

No entanto, há um vínculo estrito entre esse ideal sociopolítico-cultural incorporado aos espaços livres e a descontinuidade física dos tecidos urbanos (ao âmbito interno dos assentamentos) e das várias partes de um organismo urbano polinucleado (ao redor dos vários núcleos). Essas descontinuidades físicas são os espaços livres. Entretanto, essas descontinuidades físicas se constituem muito freqüentemente em "barreiras de espaços livres não apropriados surgem como cunhas rompendo a continuidade de assentamentos que constituem, de fato, um único sistema sócio-espacial no cotidiano de seus habitantes" ${ }^{2}$. Levantamos que a questão de desenho, central está na distribuição dos espaços livres; na conFIGURAção global do sistema de espaços livres. $E$, nessa conFIGURAção global está implícita, de acordo com a definição e o enfoque inicial de espaços livres, a distribuição da diversidade de atividades humanas em espaços fechados (desenho da cidade e desenho dos edifícios). No desenho de cada uma dessas figuras ou no arranjo da interação entre elas está a contradição, e não propriamente na existência de espaços livres que têm, no mínimo, de permitir acesso, luz e ar às edificações (além de vistas, circulação, permanência, apoio a serviços locais e urbanos, espaços para vida ao ar livre, apoio para infraestrutura e reserva para usos urbanos futuros). O que acontece é que a distribuição dos espaços livres exerce forte influência no modelo de urbanização.

\section{Os Parques São Parte dos Mecanismos de Controle Social}

Em um pequeno e interessante artigo escrito por $\mathrm{Cranz}^{3}$ sobre as mudanças dos papéis dos parques urbanos, traça-se uma evolução do "movimento americano de parques" desde meados do século XIX. Periodiza essa evolução em quatro etapas (1850-1900/1900 a 1930/1930 a 1965/1965 em diante) correspondentes a programas e desenho dos parques. Para cada um dos modelos o desenho faz uso dos mesmos elementos - água, árvores, flores, caminhos, vedos, esculturas, edificações - mas em combinações distintas e com diferentes predominâncias. Indica específicas metas sociais a atingir; diferentes são as maneiras de elaborar os mesmos elementos; a cada modelo corresponde uma intenção de contribuir para a solução de problemas decorrentes das transformações iniciadas pelos processos de industrialização e urbanização.

O pleasure garden (de 1850 a 1900), caracterizado pelos trabalhos de Olmsted ${ }^{4}$, é o parque constituído por amplo espaço (centenas de hectares), alternado em modelados suaves de pradarias e plácidas e extensas águas que serpenteiam entre as colinas onduladas. As águas refletem largas faixas de céu e massas de árvores de poucos tipos distribuídas, criando diferentes seqüências de espaços sinuosos com caminhos ondulados elaborados para bucólicos passeios concebidos de forma a sequer o tráfego de carruagens do parque desviar a atenção da atmosfera "pastoral" criada. É o cenário idealizado do campo. Flores são evitadas, pois lembram a mão do homem, a não ser como grandes campos silvestres; edifícios reduzidos ao máximo e envolvidos entre pérgolas e vedos em pedras rústicas; esculturas também são evitadas, assim como equipamentos de iluminação; quando necessários, foram depostos do visual de observador. $\bigcirc$ caminho sinuoso, com separação de veículos e pedestres, é a característica sistematicamente utilizada no modelo do período, como contraponto à rígida malha ortogonal da cidade; como os equipamentos para luz a gás, além de produtos manufaturados, iluminam as ruas da cidade e associam as edificações à cidade. A malha urbana, finita e fechada descortina-se em uma experiência de infinito nos reflexos de céu, na placidez das extensas águas. Nenhum movimento mais dinâmico nas águas sem ruídos, nenhum contraste mais significativo na vegetação, nenhum detalhe a enfatizar observações mais reduzidas. A amplitude é procurada em todos os níveis de 

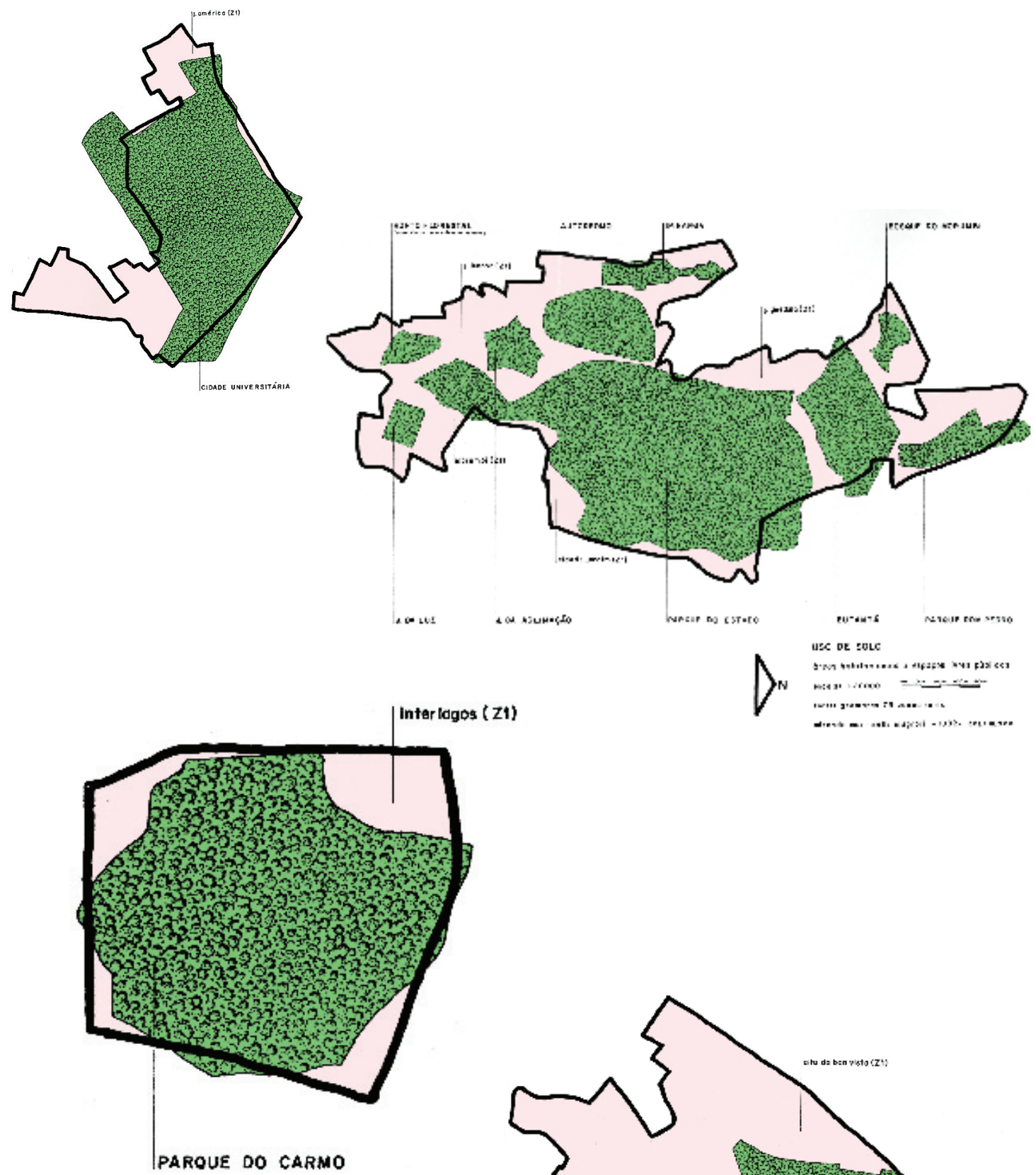

Figuras 2a, 2b, 2c e 2d: Os bairros com índices altos de espaços livres particulares (Z1) aumentam sensivelmente a extensão da urbanização. Alguns desses bairros (entre 5 e 50 hab./ha) ocupam extensão maior que

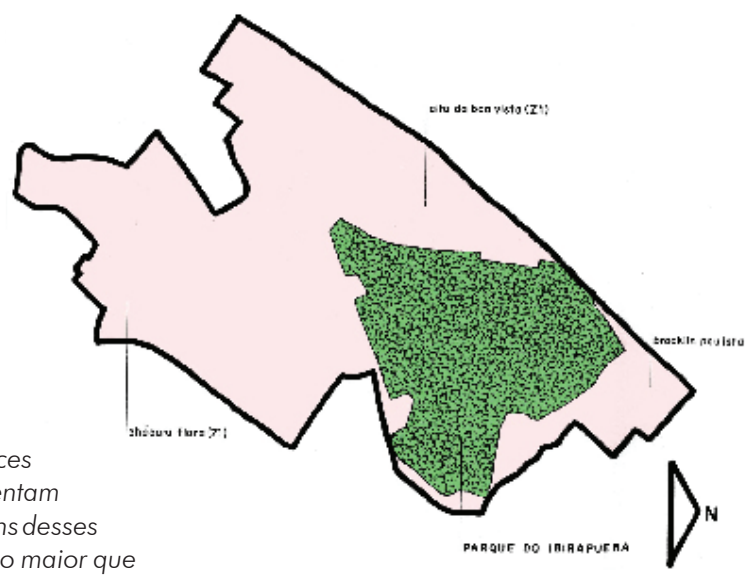
parques setoriais ou metropolitanos. Em São Paulo a totalidade desses bairros é superior à totalidade dos parques públicos Créditos: Miranda Magnoli 


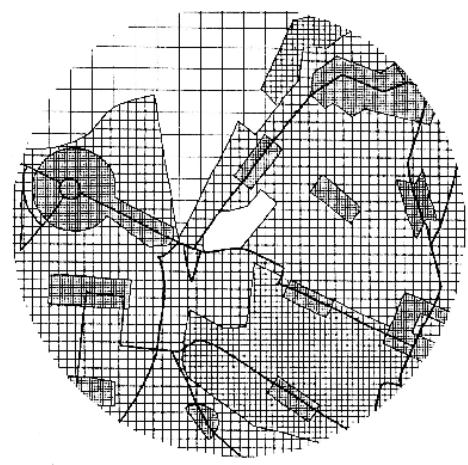

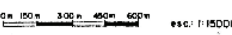

fonte: geomapas 79 zonesmento

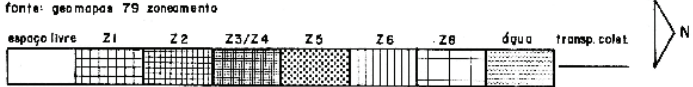

Figura 3 - Freqüentemente os parques estão distribuídos em tecidos em que é alta a taxa de espaços livres particulares (situados em Zle Z8 nos anos 1980), ocupados preponderantemente por uma população que não faz uso dos parques. Levantamento executado também indica que a população que habita em situações mais carentes não dispõe de transporte coletivo acessível aos parques Crédito: Miranda Magnoli

experiências; a ilusão bucólica é transposta além do perímetro físico do parque pela extensão da continuidade campestre, que, necessariamente, é o entorno desse espaço. São parques localizados além da periferia da cidade para aonde famílias e grupos organizados pelas associações religiosas e protetoras da moral e dos bons costumes são levados semanalmente para passear, andar de barco, alugar carruagens, ouvir concertos, fazer piqueniques.
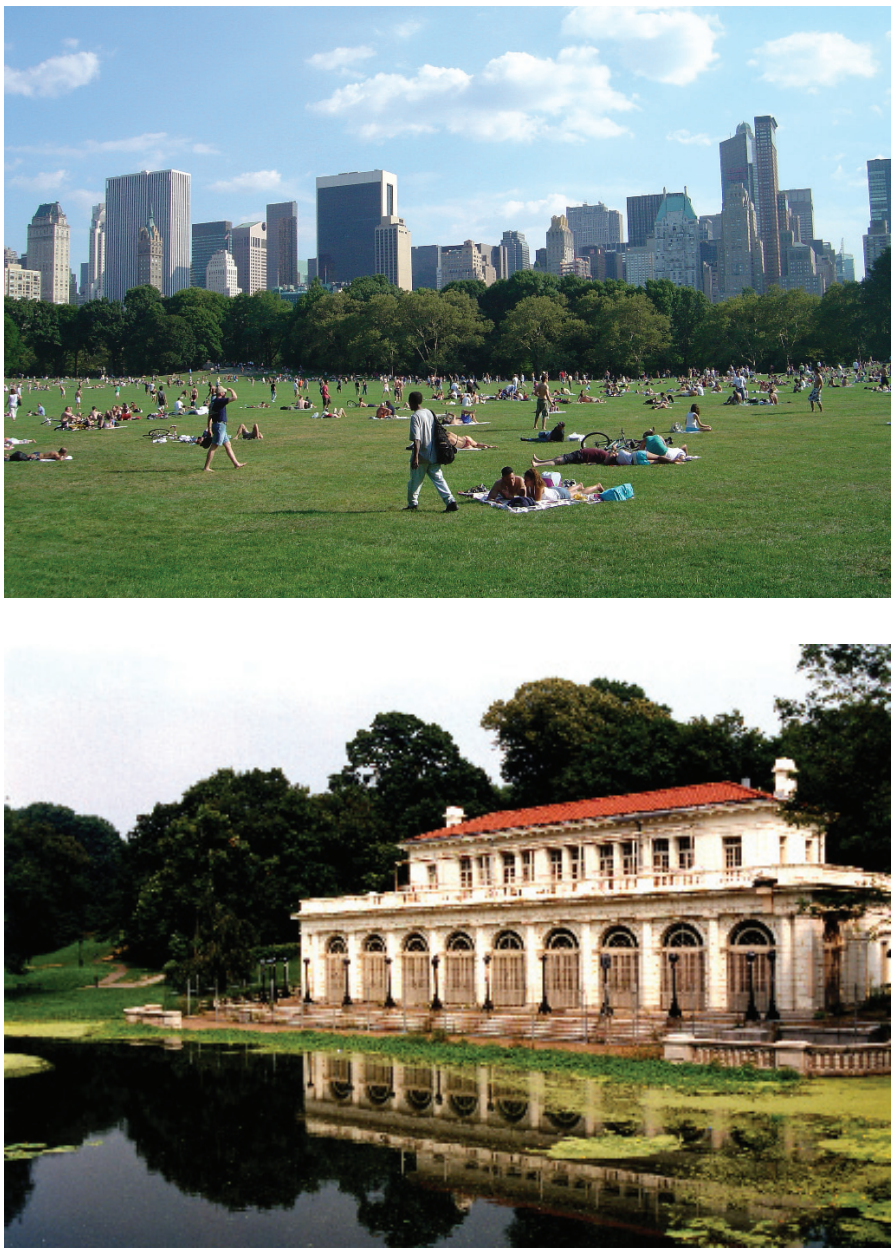

Foto 4: Vistas gerais - Central Park, Nova York

Crédito: Silvio Macedo, 2005

Foto 5: Vistas gerais - Prospect Park, Nova York

Crédito: Silvio Macedo, 2001 


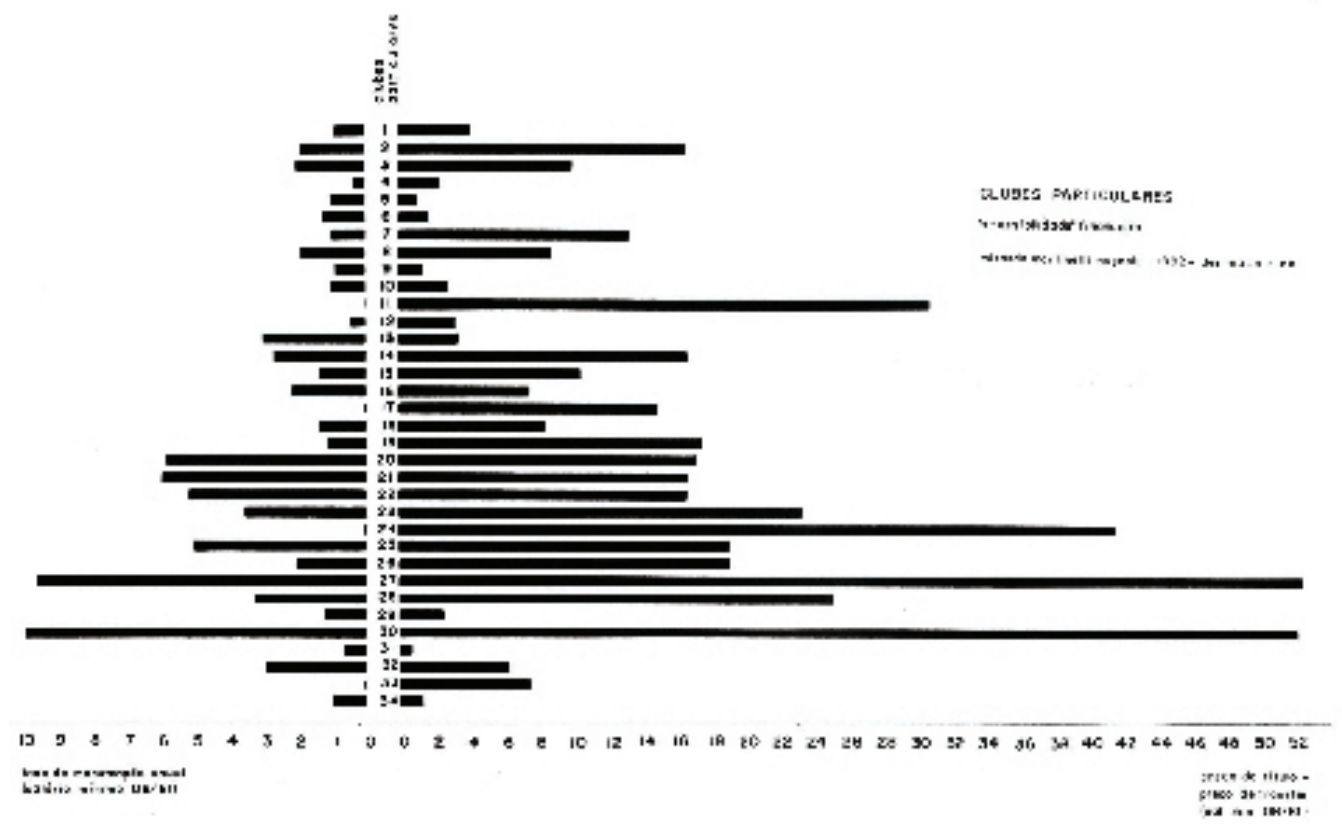

Figura 4 - A existência de vários clubes pode dar a impressão de disponibilidade de espaços recreacionais. Porém, é restrita a acessibilidade a esses equipamentos perante as condições de ingresso; os preços dos títulos e as taxas mensais de manutenção marginalizam a maior parte da população; outros poucos, públicos, são restritos a grupos (ex.: centros de campi)

Crédito: Miranda Magnoli

As atividades, sempre em contraste com a rotina urbana, não requerem participação, que poderia ocorrer no trabalho e na produção e voltam-se para experiências marcadamente contemplativas, passivas; sequer atividades artesanais, similares à produção manufatureira, são aceitas; assim, exercícios mais exigentes em esforços físicos ou em repetição, memorização e sistematização. Em um ambiente para grupos e atividades familiares, são enaltecidas e desencorajadas as formas de comportamento consideradas adequadas e inadequadas. É proscrito o alcoolismo, marginalizados a prostituição, jogos de azar e outras manifestações consideradas da cultura popular e da baixa condição cultural e moral dos imigrantes. As várias classes sociais no campo são nitidamente separadas em todos os aspectos; nas cidades, o discurso democrático é mantido como aspiração que não deve ser arranhada pela urbanização e industrialização. $\bigcirc$ parque oferece um espaço de interação, visual, das várias classes.

São parques localizados além das periferias das cidades; vistos e divulgados como verdadeiros "pulmões" a serem oferecidos semanalmente - as expansões em extensão e os prolongados horários de trabalho já não permitiam a proximidade espacial diária com o campo, com os espaços "naturais" que permitiam diminuir os rigores e agruras da industrialização americana da época. Como elemento definitivo para a implantação desses novos espaços da urbanização pesaram as epidemias as quais, anvalmente, assolavam as cidades e particularmente as áreas concentradas no verão. $\bigcirc$ Central Park foi o antídoto à epidemia de cólera que grassou em Nova York em 1852.

São atuais duas correntes de pensamento que, fundamentalmente, elaboram:

- O programa, mais do que dar alívio ao trabalhador exausto, procurava estimular uma parte relegada da mente humana: aquela da percepção do espaço, das formas, da apreciação artística ao invés da lógica, da racionalização (analogia ao modelo de atividades dos hemisférios direito e esquerdo nos cérebros humanos); 
- esses parques seriam um freio ao perigo visto pelas elites morais em relação aos ideais morais de difícil controle nas cidades. Enriquecendo com negócios urbanos, teriam preferido viver no campo: finos e educados fazendeiros. Os imigrantes rurais no período, freqüentemente, idealizaram a cidade como o lugar de animação, de importância ao anônimo, de luzes, sons, liberdades maiores que nas comunidades agrícolas e, como subsídio básico, de oportunidade de salários em dinheiro e não mais em moradia, alimentação e eventuais espécies. Fica a questão: onde e como seriam esses espaços, se pretendessem expressar a aração e as esperanças depositadas nas cidades?

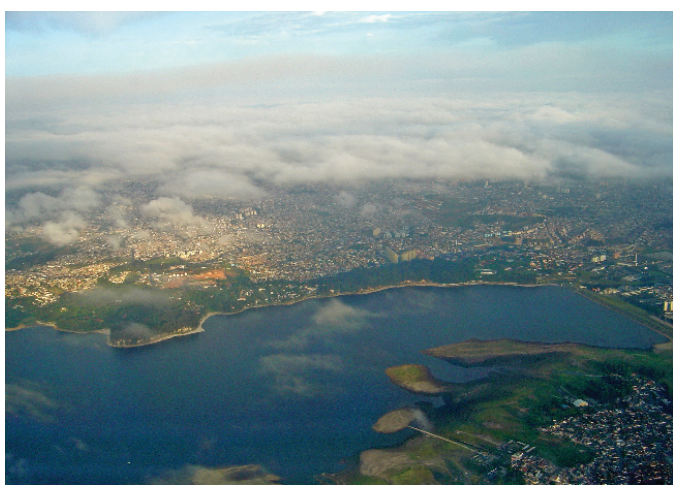

Foto 6: Vista aérea - Represa Guarapiranga Crédito: Silvio Macedo, 2005

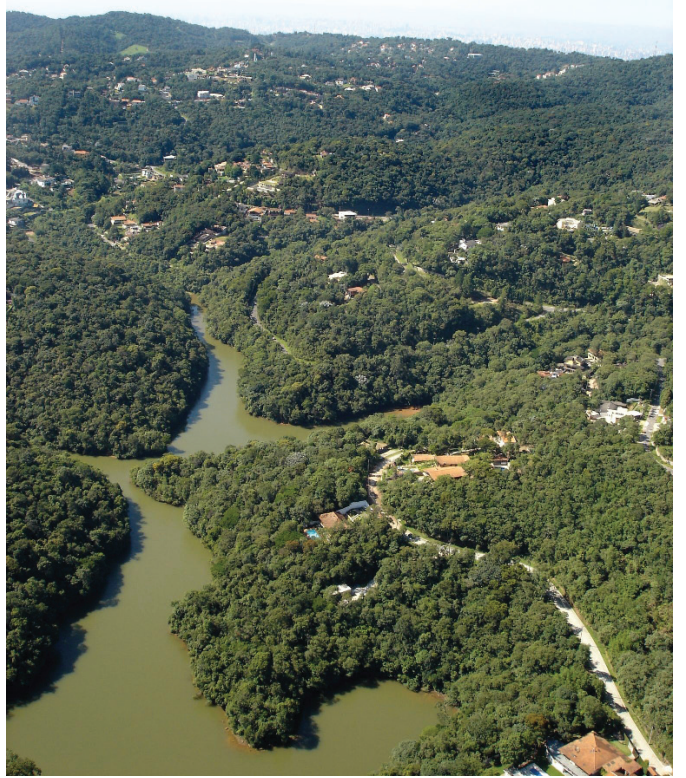

Figura 5 - As áreas de reservatórios da infra-estrutura metropolitana, bem como reservas florestais não têm sido propostas para apropriação pela população. A polivalência de usos é possível e adequada em relação à urbanização, desde que caracterizadas as restrições na gestão do projeto, implantação e utilização (Represa Mairiporã)

Leonardo Coelho, 2006
O período subseqüente, de 1900 a 1930, é o de maiores transformações na evolução dos parques: é o do reform park ou também playground period. Dois são os aspectos que o fundamentam na necessidade de mudanças: playgrounds e espaços locais. Passam a internalizar-se no urbano, construindo áreas para as crianças. Em pouco tempo a aspiração é estendida e implantada para todas as faixas etárias em organizações programadas e supervisionadas por idades e sexos. É decorrência óbvia que os espaços sejam reduzidos, já que próximos às habitações e aos locais de trabalho. Também, totalmente ocupados em caixa de areias para brinquedos, exercícios físicos e classes e ensinamentos subsidiários de higiene, saúde, alguma profissionalização e naturalização americana para os imigrantes. Os edifícios ocupam boa parte do espaço (visto que reduzido) para permitir esse tipo de programação a qual se desenvolve além trabalho, para todas as idades ocupadas na indústria. Ginásticas, atividades esportivas, representações teatrais sempre de fundo histórico relacionado à criação da nação americana, são parte da educação de orgulho cívico o qual os vários líderes de grupos, idades e sexos impõem. A morfologia urbana tem aparência contínua com o aspecto das fábricas, das habitações, do comércio prolongando-se em alguns dos tantos espaços previstos para atividades programadas.

É desse período a cisão entre os grupos ainda ligados à idéia do parque do outro período e esse setor que se classifica ligado à recreação. É a discussão ainda comum entre nós, entre recreação "ativa" e "passiva": uma seria para participação e outra para apreciação!

O começo do século é indicativo do aparecimento de vários diferentes movimentos sociais em todo o mundo. As elites empresariais e filantrópicas ao orientarem, com a competência que se assumiam, as necessidades das classes 
trabalhadoras, indicavam a aceitação e racionalização concreta e objetiva da cultura industrial dentro das normas, regulamentos e valores das leis anglo-saxônicas. É uma pergunta que o autor dos estudos faz a si mesmo: como seria o urbano e o desenho dos espaços, se viesse à tona a máquina política da época, os favoritismos e as manipulações das elites e se o trabalhador pudesse distribuir as cervejarias que almejava e as organizações por grupos étnicos, raciais e minoritários os quais germinavam entre eles?

As transformações posteriores à Primeira Guerra Mundial, os movimentos dos trabalhadores da década de 1920 convergem para a institucionalização da recreação como função do poder municipal que se estabelece por volta de 1930. É usada para o período de 1930 a 1965 a expressão recreação, aliás recreation facility significando a distribuição assegurada para todos, em âmbito nacional, no cotidiano, em eventos, jornadas, em tal porte, que se passa aplicar a execução e implantação seriada e multiplicada de estádios, grandes piscinas, quadras, arquibancadas e painéis de jogos e esportes. São programados eventos esportivos de massa, desportes em grupos grandes. É maciça a participação na recreação considerada ativa. Com a evolução, as propostas se refinam para os deficientes físicos, para os idosos, os cegos, os aposentados. A padronização se estende em todos os locais, em toda a nação, em todas as propostas. Nas crises da Depressão e da Segunda Guerra Mundial esses parques assumiam boa parte da sustentação moral oferecida pelos órgãos federais, como demonstração de progresso, liberdade e democracia. É um período de grande aumento da classe média profissional e de uma classe que se sente participante dos grupos decisórios, uma classe nova entre os proprietários e os trabalhadores: a administração eficiente e sua capacidade quanto aos serviços para a comunidade são os aspectos principais a regerem as questões de classe. No aspecto da urbanização, esta se estende em amplas áreas de baixa densidade, habitações unifamiliares na periferia da cidade entre gramados contínuos e entre edificações: procura-se um estilo de vida ligado ao rural, habitando-se na periferia e trabalhando-se na cidade. Na cidade, em espaços concentrados, o poder público deveria oferecer para os habitantes urbanos as facilidades que estariam nas periferias como estrutura de vizinhança, a qual seria propiciada pelos espaços de interação entre as casas.

Os estudos urbanísticos do pós-guerra, especialmente ingleses, e o racionalismo na arquitetura distribuíam pelo mundo índices de áreas verdes classificadas em playlots, playgrounds, playfields e outros, de forma similar às casas, escolas, hospitais, comércio, setores industriais e sistemas de trânsito. A correta hierarquização e a distribuição sistematicamente planejada nas cartografias, desde a escala local até a nacional, faria com que os parques contribuíssem com todos os requisitos técnicos para uma sociedade justa, equilibrada, harmoniosa, ordenada. Talvez feliz, também.

De 1965 a 1986 as modificações são intensas e extensas. A cidade é essencialmente vista como toda ela, em ruas, largos, praças, parques, a ser assumida como um espaço de vida diversificada, heterogênea, que espera poder inebriar-se em revitalizações mais duradouras ou transitórias e eventuais. Os fenômenos da automação, do contínuo acréscimo do lazer são de difícil integração com a deterioração e vandalização em equipamentos coletivos e largas áreas das zonas centrais.

Essa evolução não é a nossa. A nossa está para ser estudada, refletida, debatida, elaborada. Uma série de circunstâncias da sociedade do país mais rico do planeta e do excepcional desenvolvimento do paisagismo americano, na prática, nas instituições acadêmicas e no poder público, faz com que diversos sejam os aspectos nos quais nos cabe um pensamento mais cuidadoso e abrangente. No mínimo e, preliminarmente, podemos observar que a conFIGURAção, a conFORMAção na história dos parques reflete, mais do que se quer pensar, intenções sociais imediatas em uma atitude e filosofia subjacentes em relação ao fenômeno urbano. Os modelos, em sua seqüência, vão se sobrepondo por partes em espaço e em tempo nem sempre transparentes em diferentes contextos e diferentes populações. 
Nossos espaços e nossas cidades não constituem o resultado de um processo homogêneo em uma cadeia histórica, que possa amalgamar o povo, a nação, o Estado. Não podem ser vistos como um acomodamento de instituições que visem à participação plena de todos os cidadãos na condução de seus desígnios para os ambientes de vida. As observações as quais iniciamos ${ }^{5}$ são ainda muito preliminares e contêm grandes lacunas. Limitam-se, no momento, a levantamentos de caráter espacial nos vários níveis escalares da região metropolitana de São Paulo - insuficientes até nos levantamentos para as explicações dos modelos urbanos, para individualizar as separações entre atividades físicas, manuais e as intelectuais, artísticas, "espirituais" independentes; não conseguem revelar idéias, regras, valores, normas daqueles que teriam a competência para essas decisões; ficam a dever na compreensão das expressões, das exteriorizações, nas formas concretas com que a cultura se manifesta; as formas de convívio em espaços de presença humana diversificada, de caráter desigual, heterogêneo, plural, não emergem facilmente pelos códigos representados na linguagem do tratamento do espaço.

Por outro lado, são múltiplas as situações que deverão ser estudadas - por nós todos; não creio que possamos nos valer de alguns poucos processos urbanos e daí generalizar. A população do país não pode ser vista de forma homogênea só por causa da língua, do futebol e alguns outros poucos hábitos comuns. São inúmeros os modos de vida, as expressões culturais vigentes, as tradições, os interesses, as representações; a unificação por uma síntese geral que é, no mínimo, problemática. O papel do Estado é, no mínimo, controverso, especialmente na constituição da Nação. Esses espaços urbanos, enquanto parte de expressão cultural das culturas sociais, envolvem as capacidades das sociedades para transformar as situações existentes em situações com o sentido do novo; para um campo de ações e pensamentos que ultrapassem experiências, desequilibrem, reinventem modos estabelecidos de ver, ouvir, pensar sem padronização, massificação, simplificação, repetição. São formas diferenciadas as quais, possivelmente, surgirão por meio de grupos, comunidades, lugares, tempos, espaços e conteúdos. Procuramos imaginar que talvez alguns pontos possam ter despertado algum interesse e empenho para questões que têm sido consideradas uma espécie de luxo, de supérfluo, alheia às "coisas sérias".

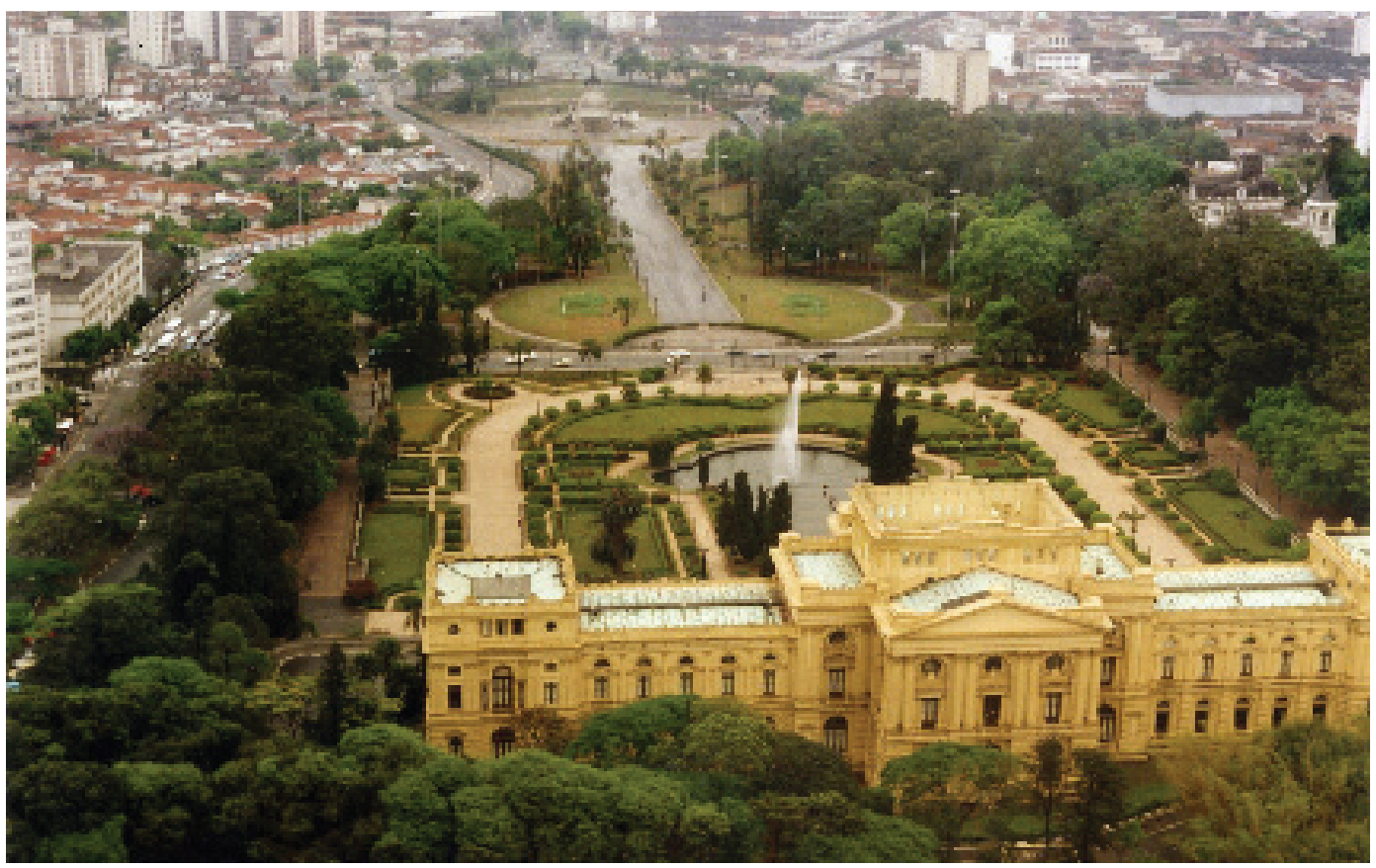

Foto 7 - Parque da Independência, desenho da década de 1940

Crédito: Silvio Soares Macedo 

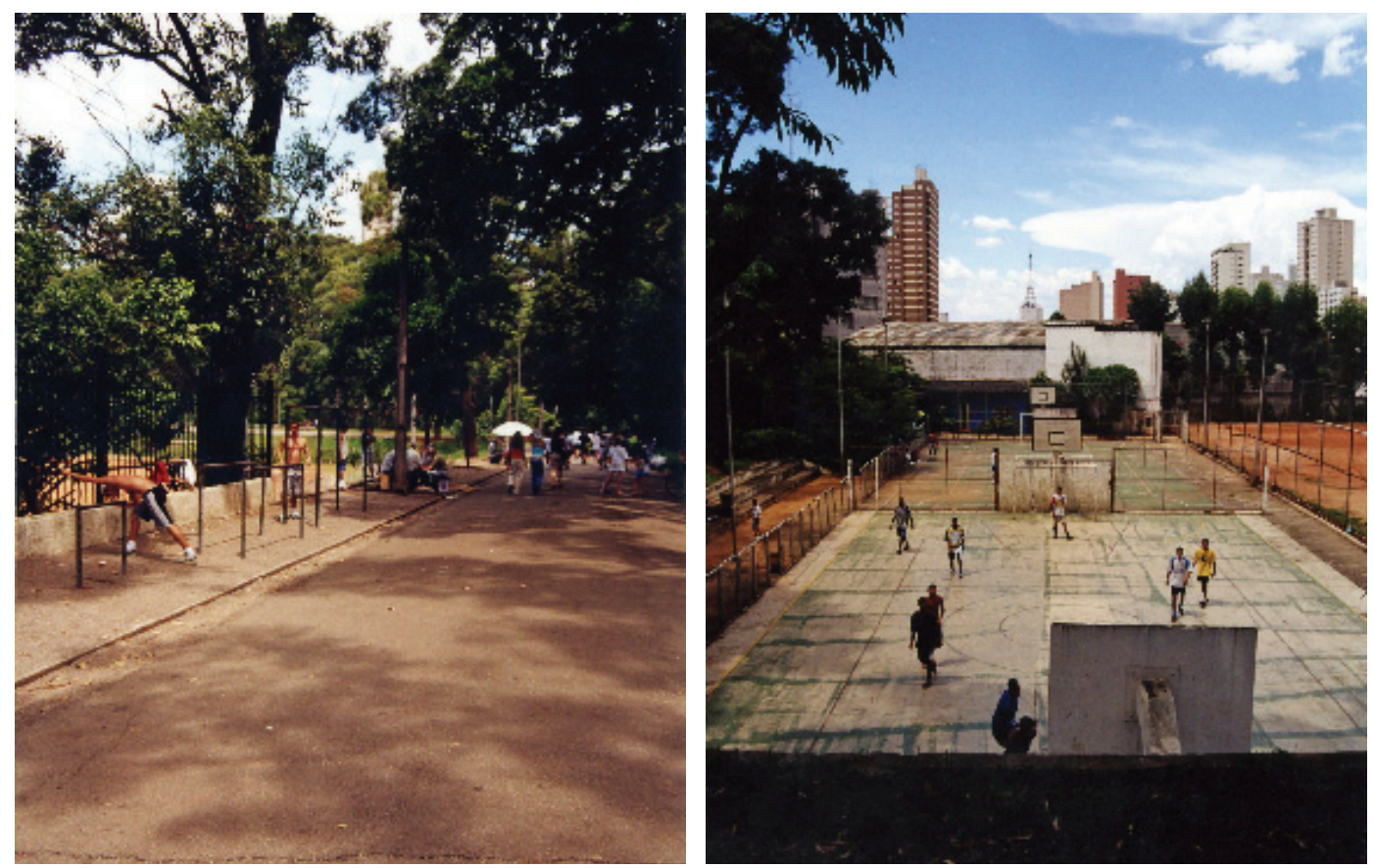

Fotos $8 a$ e $8 b$ - Parque da Aclimação, adaptado na década de 1960 Crédito: Josefina Capitani

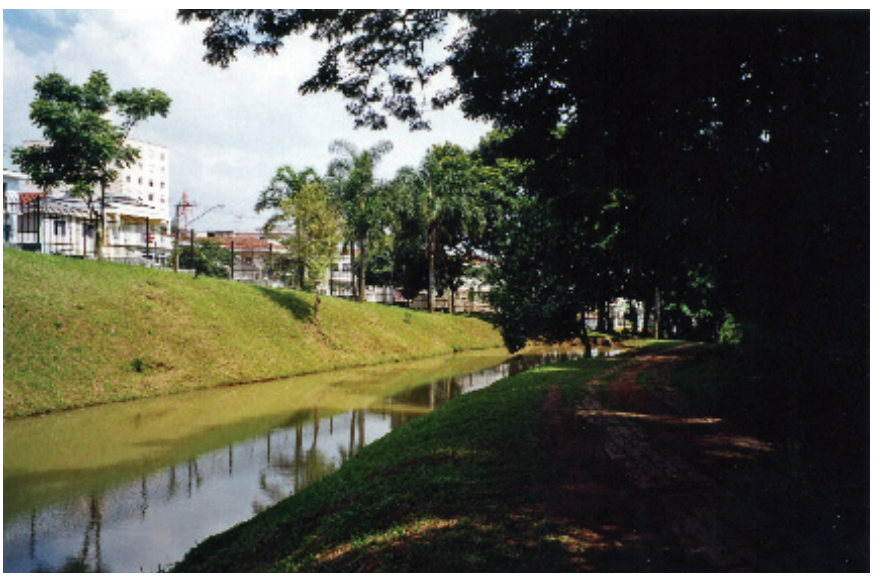

Fotos 9a e $9 b$ - Parque Vila dos

Remédios, executado nos anos 1970

Crédito: Sérgio Ortiz, 2003

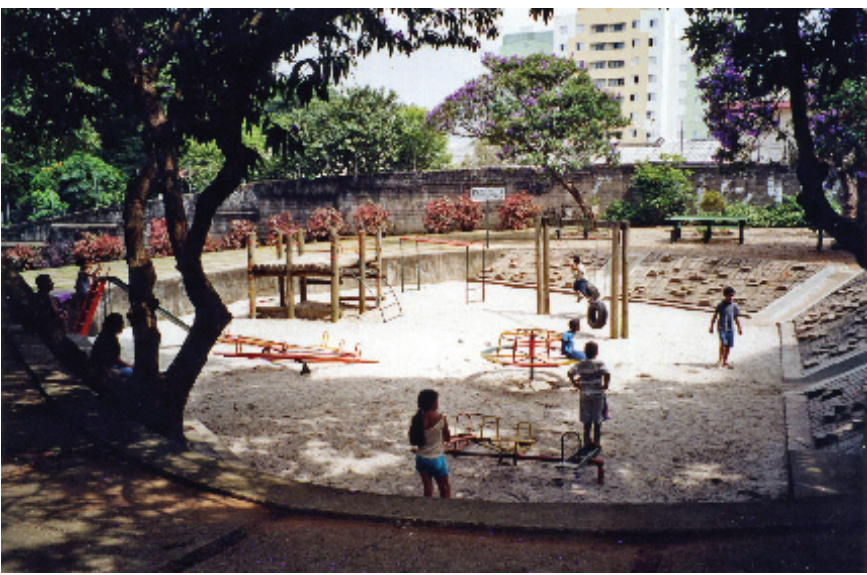



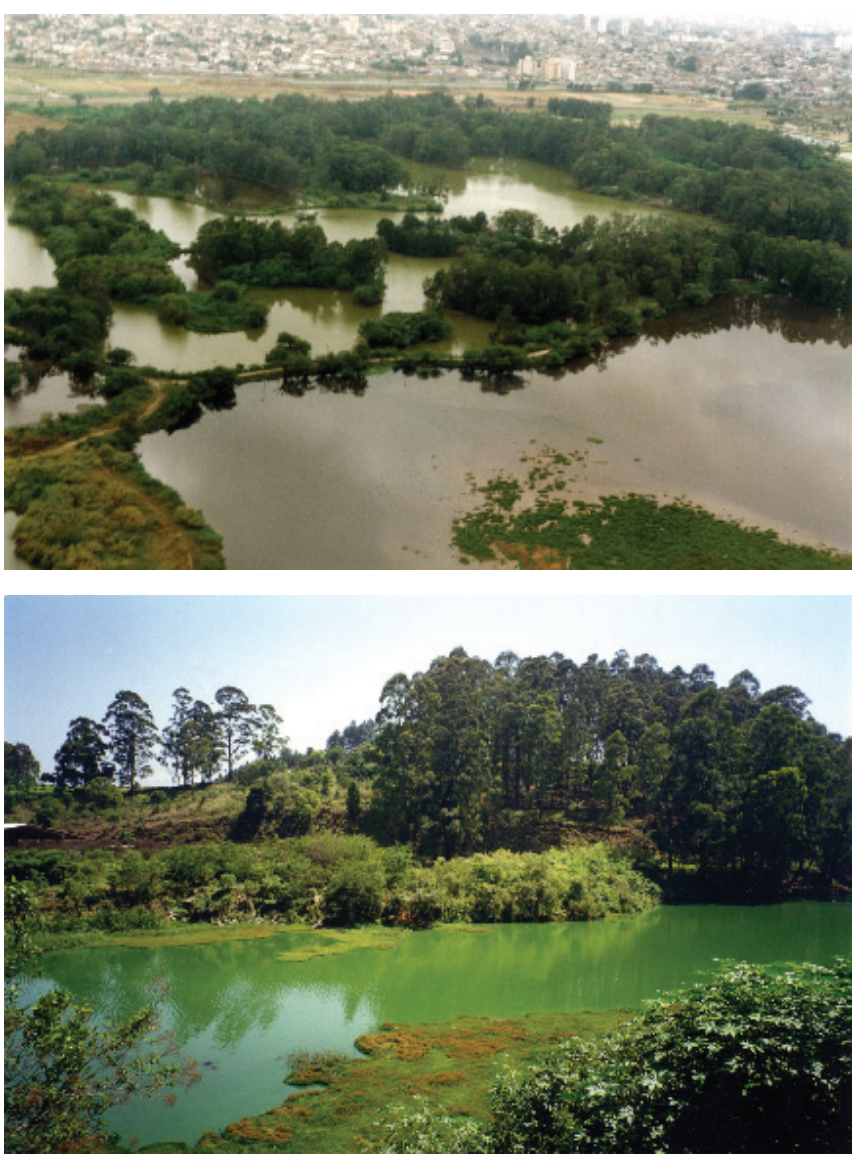

Parque Ecológico do Tietê dos anos 1980

Foto 10 - Núcleo Tamboré

Crédito: Luciana Mantovani

Foto 11 - Núcleo Cangaíba

Crédito: Silvio Soares Macedo

\section{Notas}

(1) TANKEL, Stanley. La importancia del espacio libre en si modelo urbano. In: WINGO, Lowdon. Ciudades y espacio, el uso futuro del suelo urbano. Barcelona: OIKOS-TAU, 1976. (Colección de Urbanismo).

(2) HOLANDA, Frederico de. Arquitetura como estruturação social. In: FARRET et al. O espaço da cidade - Contribuição à análise urbana. São Paulo: Projeto, 1985.

(3) CRANZ, Galen. Changing roles of urban parks - From pleasure garden to open space. Landscape, n. 2, 1978.

(4) Referimo-nos a Frederick Law Olmsted, considerado o pai do paisagismo americano. Nasce em Connecticut, em 1822, e durante os 81 anos de vida exerceu várias profissões que contribuíram para sua compreensão da época; em sua atividade de arquiteto paisagista, que ele criou nos EUA, procurou transferir para os projetos suas metas para as necessidades urbanas. Cresceu no campo, viajou à China em 1846 e em 1850 à Inglaterra; nessa viagem ficou vivamente impressionado com a vida rural inglesa e com a paisagem do parque "natural" inglês. Em 1858 ganha, com Calvert Vaux, o concurso para o projeto do maior parque de Nova York: o Central Park, hoje bastante transformado internamente, mais ainda se podendo notar características essenciais. O sucesso desse trabalho levou a vários outros em Nova York, Chicago, Boston, Albany, Buffalo, Rochester, San Francisco, Newark, Philadelphia, Montreal, Detroit, Hartford, Trenton, Lovisville, Milwakee e Kansas City. São parques, novos bairros, exposições mundiais, áreas institucionais, campi universitários, áreas de preservação e sistema de parques. É também devida a Olmsted a difusão dos parques nacionais e a criação do parque nacional de Yosemite Valley. Para a época, a visão de Olmsted é de largo espectro e fôlego, especialmente quando analisada em confronto com os moldes europeus. É decorrência da contribuição de Olmsted, na visão global dos espaços do território e na compreensão da paisagem como interação entre os processos do meio físico e dos processos da intervenção antrófica, o surgimento da arquitetura paisagística como área disciplinar criada, inicialmente, na Universidade de Harvard em 1900, junto da Lawrence Scientific-Scholl. Seu brilho, visão abrangente e local não conseguiriam manter-se nas décadas subseqüentes, apesar do avanço profissional e disciplinar que se estende pelo país. Suas lições seriam retomadas no 
início da década de 1970 com as grandes transformações da ciência, da tecnologia, dos comportamentos sociais e nas expressões das atitudes humanas.

(5) Referimo-nos a estudos iniciados em MAGNOLI, Miranda Martinelli. Espaços livres e urbanização: Uma introdução a aspectos da paisagem metropolitana - tese de livre-docência, FAUUSP. São Paulo, 1982. Esses estudos vêm sendo retomados por novos pesquisadores dentro do Programa de Área de Pesquisa Planejamento da Paisagem do Departamento de Projeto da FAUUSP.

\section{Bibliografia}

CRANZ, Galen. Changing roles of urban parks - From pleasure garden to open space. Landscape, n. 2, 1978.

HOLANDA, Frederico de. Arquitetura como estruturação social. In: FARRET et al. O espaço da cidade - Contribuição à análise urbana. São Paulo: Projeto, 1985.

MAGNOLI, Miranda Martinelli. Espaços livres e urbanização: Uma introdução a aspectos da paisagem metropolitana. Tese (Livre-docência) - Faculdade de Arquitetura e Urbanismo, Universidade de São Paulo, São Paulo, 1982.

TANKEL, Stanley. La importancia del espacio libre en el modelo urbano. In: WINGO, Lowdon. Ciudades y espacio, el uso futuro del suelo urbano. Barcelona, 1976. (Colección de Urbanismo OIKOS-TAU).

Obs.: Texto publicado originalmente em "Desenho Urbano: Anais do II SEDUR - Seminário sobre Desenho Urbano no Brasil". 